\title{
Integration of Cadherin Adhesion and Cytoskeleton at Adherens Junctions
}

\author{
René Marc Mège ${ }^{1}$ and Noboru Ishiyama ${ }^{2}$ \\ ${ }^{1}$ Institut Jacques Monod (IJM), CNRS UMR 7592 and Université Paris Diderot, Paris, France \\ ${ }^{2}$ Princess Margaret Cancer Centre, University Health Network, TMDT 4-902, Toronto, Ontario, Canada \\ Correspondence: rene-marc.mege@ijm.fr; noboru.ishiyama@uhnres.utoronto.ca
}

The cadherin-catenin adhesion complex is the key component of the intercellular adherens junction (AJ) that contributes both to tissue stability and dynamic cell movements in epithelial and nonepithelial tissues. The cadherin adhesion complex bridges neighboring cells and the actin-myosin cytoskeleton, and thereby contributes to mechanical coupling between cells which drives many morphogenetic events and tissue repair. Mechanotransduction at cadherin adhesions enables cells to sense, signal, and respond to physical changes in their environment. Central to this process is the dynamic link of the complex to actin filaments (Factin), themselves structurally dynamic and subject to tension generated by myosin II motors. We discuss in this review recent breakthroughs in understanding molecular and cellular aspects of the organization of the core cadherin-catenin complex in adherens junctions, its association to F-actin, its mechanosensitive regulation, and dynamics.

\begin{abstract}
A defining feature of tissues is adhesion between cells at specialized intercellular junctions, known as adherens junctions, which involves $\mathrm{Ca}^{2+}$-dependent cell-cell adhesion molecules of the cadherin family (e.g., E-cadherin in epithelia) and their associated catenins. The cadherin/catenin adhesion complex is a key component that contributes to epithelial and nonepithelial tissue stability and dynamic cell movements. This complex bridges neighboring cells and the actomyosin cytoskeleton, and thereby contributes to mechanical coupling between cells which drives many morphogenesis events and tissue repair. The importance of this coupling is particularly exemplified in mammalian embryonic cell compaction and ingression (Samarage et al. 2015), and during api-
\end{abstract}

cal constriction (Weng and Wieschaus 2016) and convergent extension of the germ band layer in Drosophila (Guillot and Lecuit 2013). It is also critical during wound healing and gap closure of epithelial mammalian cells monolayers (Liu et al. 2010; Vedula et al. 2012; Doxzen et al. 2013; Bazellieres et al. 2015). Thus, understanding the molecular and cellular biology of the cadherin cell adhesion machinery, including associated partners and F-actin, and of adherens junctions, is a prerequisite to acquiring a comprehensive understanding of key developmental and pathological processes common to multicellular organisms from flies and worms to humans. Fortunately, recent advances in combining classical cell biology, live cell imaging, biomechanical, and biophysical tools have

Editors: Carien M. Niessen and Alpha S. Yap

Additional Perspectives on Cell-Cell Junctions available at www.cshperspectives.org

Copyright (C) 2017 Cold Spring Harbor Laboratory Press; all rights reserved; doi: 10.1101/cshperspect.a028738

Cite this article as Cold Spring Harb Perspect Biol 2017;9:a028738 
allowed us to gain a deeper understanding of the integration of the processes of cadherin adhesion and association to the actin cytoskeleton that lead to the formation of adherens junctions which are stable enough to maintain tissue cohesion, but also plastic enough to allow cell rearrangement during development. We will focus here on recent progress in unveiling the deep molecular and cellular mechanisms of cadherin adhesion which include multiscale clustering and dynamic association to the contractile actomyosin cytoskeleton. We will discuss the challenge of understanding cell adhesion dynamics at multiple scales in living cells, an issue that is common to understanding the behavior of many self-assembled modules in living matter. We will discuss the issues which become accessible now to investigators thanks to new developments in proteomics, structural biology, imaging, quantitative biology, modeling, and biophysics.

\section{HISTORICAL PERSPECTIVE, A FEW MISUNDERSTANDINGS}

The present knowledge about adherens junctions, their link to actin and their dynamic nature, started with a misunderstanding back in the 1970s between two early fields of cell biology. The first, and older one, is intrinsic to the emergence of cell biology: it is the characterization of cellular structures, compartments and organelles thanks to the development, then use by cell biology pioneers, of the electron microscope. This allowed Palade and others to describe in epithelial cells portions of plasma membranes at the intercellular sites where neighboring membranes come into proximity with one another (Farquhar and Palade 1963). Among them was a class of junctions found in many tissues that were collectively called adherens junctions, which are located below tight junctions at intermediate position within the epithelial apico-lateral complex in vertebrate cells (named zonula adhaerens in the seminal paper of Farquhar and Palade [1963]). These junctions are characterized by an intercellular spacing of around $20 \mathrm{~nm}$ that is maintained throughout the junction and extensive conden- sation of cytoplasmic fibrils along either side of the junction. They differ from desmosomes, which are found at more basal positions and characterized by a wider intercellular space bisected by an intermediate line. Desmosomes have bundles of cytoplasmic fibrils converging into dense plates that are separated from the inner leaflets of the cell membrane by a zone of low density. Because of this morphological description in fixed adult, highly structured, tissues, intercellular junctions have been considered as stable attachment points appearing in mature tissues.

The second angle of attack comprises the studies of cell adhesion initiated $10-15$ years later under the leadership of pioneers such as Edelman and Takeichi who were puzzled by morphogenetic processes appearing during the shaping of organisms. They were clearly inspired by two developmental biologists: Wilson (1907) and Holtfreter (1939), (see Holtfreter 1964 for the translation in English). By developing dynamic tools to study and quantify cell-cell adhesion as short term aggregation of live cells, they defined cell-cell adhesion as a dynamic process associated with morphogenesis (Urushihara et al. 1976; Brackenbury et al. 1977; Thiery et al. 1977). Amazingly for a latterday cell biologist, both fields ignored each other up to the 1980s, when the expression of cadherins, identified as cell adhesion molecules thanks to aggregation assays, was shown to induce the formation of adherens junctions when transfected in cells (Matsuzaki et al. 1990; Mège et al. 1988). As an illustration, $N$ (neural)-cadherin was functionally and biochemically characterized, then cloned simultaneously by the Edelman and Takeichi groups (Hatta et al. 1988; Matsuzaki et al. 1990), and turned out to be the adherens junction cell adhesion molecule (A-CAM) characterized by Volk and Geiger (1986). This precipitated the merger between the two views, which has only strongly evolved along the past 10 years toward an integrated view of intercellular junction dynamics on the time scale of a cell's lifetime thanks to dynamic live cell imaging (Adams et al. 1998; Thoumine et al. 2006; Guillot and Lecuit 2013; Heisenberg and Bellaiche 2013; de Beco et al. 2015). 
In the 1980s, functional perturbation and immunoprecipitation experiments showed that cadherin function required the integrity of the actin cytoskeleton, and that the cadherin cytoplasmic domain associates with intracellular cadherin-associated proteins, namely catenins $\alpha$ and $\beta$ (Nagafuchi and Takeichi 1988; Ozawa et al. 1989). These catenins, as well as another protein described as a cadherin cytoplasmic tail binding partner, p120-catenin (Reynolds et al. 1994), rapidly appeared together with the cadherin molecule itself as obligatory subunits of a multimeric plasma membrane homophilic adhesion receptor, the cadherin/ catenin complex, which requires association to F-actin for its function (Mège et al. 2006). Although detailed biochemical analysis of the cadherin/catenin complex published in 2005 cast doubt on the nature of this link to F-actin
(Nelson and Weis 2016), it is clear now, after almost a decade of controversy, that the complex binds F-actin directly via $\alpha$-catenin, which is a bona fide actin binding protein, with $\beta$-catenin making the link between cadherin cytoplasmic tail and $\alpha$-catenin (Fig. 1). The novel insight acquired along the past years is that this association may require forces developed by the myosin II motors and involve additional F-actin-binding/bundling proteins such as vinculin, as developed further in this review (Yonemura et al. 2010; Buckley et al. 2014).

\section{THE CORE CADHERIN/CATENIN COMPLEX}

Classical cadherins found at the adherens junctions are $\mathrm{Ca}^{2+}$-dependent cell-cell adhesion molecules composed of an extracellular domain with five cadherin repeats, a transmembrane

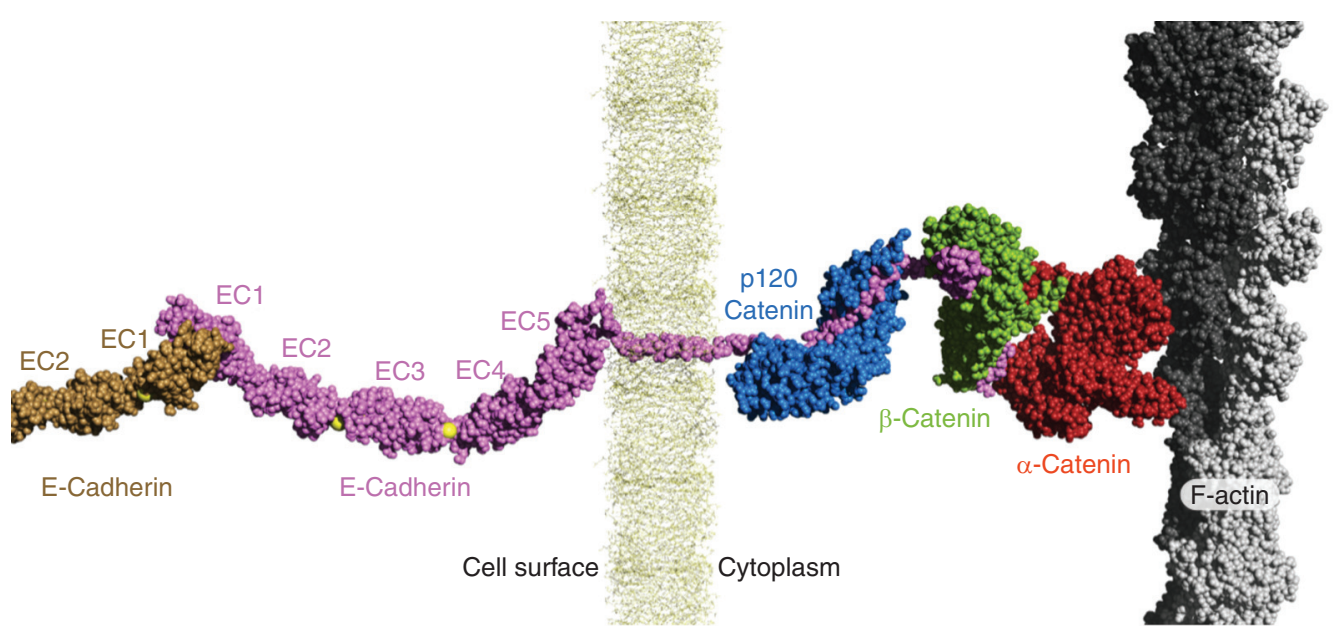

Figure 1. Three-dimensional model of the E-cadherin-catenin cell adhesion complex associated with F-actin. The E-cadherin-catenin cell adhesion complex is a major component of adherens junctions that mediate calcium-dependent cell-cell adhesion. Ectodomains of E-cadherin cell adhesion receptors (orange and pink) from adjoining cells engage in the extracellular strand-swap trans interaction. The cytoplasmic region of Ecadherin binds directly to $\beta$ - and p120-catenins, and indirectly to the F-actin-binding protein $\alpha$-catenin through $\beta$-catenin. $\alpha$-catenin binds directly to F-actin through its carboxy-terminal actin-binding domain or indirectly by associating with other F-actin-binding proteins, such as vinculin (not shown here). The model is based on the following crystal structures: E-cadherin ectodomain EC1-5 trans-dimer bound to calcium (yellow spheres) (PDB ID: 3Q2V) (Harrison et al. 2011); p120 catenin (blue) bound to E-cadherin (PDB ID: 3L6X) (Ishiyama et al. 2010); $\beta$-catenin (green) bound to E-cadherin (PDB ID: 1I7W) (Huber and Weis 2001); $\alpha$ E-catenin (red) (PDB ID: 1DOW, 4IGG and 4K1N) (Pokutta and Weis 2000; Ishiyama et al. 2013; Rangarajan and Izard 2013); and F-actin (light and dark gray) (PDB ID: 3B63) (Cong et al. 2008). The plasma membrane is shown in pale yellow lines. Model building was performed with Coot (Emsley and Cowtan 2004). The molecular image was produced using PyMOL (DeLano 2008). 
domain and a carboxy-terminal cytoplasmic domain (Takeichi 2014) (Fig. 1). The extracellular domain is responsible for homophilic interactions between cadherin molecules expressed at the surface of neighboring cells (Boggon et al. 2002). This trans interaction involves weak stepwise dimerization of cadherin ectodomains through transient $\mathrm{X}$-dimer then strand-swap dimer formation, with dissociation constants ranging from $\sim 100-900 \mu \mathrm{M}$ for E-cadherin (Harrison et al. 2011; Kudo et al. 2016). During cadherin synthesis in the ER, the armadillo-repeat family proteins p120-catenin and $\beta$-catenin (alternatively $\gamma$-catenin in some cell types) assemble onto the cytoplasmic domain. While p120-catenin has an essential function in regulating the stability of cadherin-catenin complexes at the plasma membrane (Peifer and Yap 2003), $\beta$-catenin interacts with the actin binding protein $\alpha$-catenin (Figs. 1, 2). The integrity of the cadherin-catenin complex as well as its association with the actin cytoskeleton were recognized very early on as a prerequisites for cell-cell adhesion (Nagafuchi and Takeichi 1988). It has also been known for some time that the $\alpha$-catenin $/ \beta$-catenin heterodimer binds in a stoichiometric complex to cadherins (Aberle et al. 1994). Subsequent biochemical studies challenged the direct linkage between the cadherin-catenin complex and F-actin (Yamada et al. 2005). However, recent data reconciled these opposite views by considering the role of mechanical force as a central element required for binding the cadherin-catenin complex to F-actin (Buckley et al. 2014; Yao et al. 2014b).

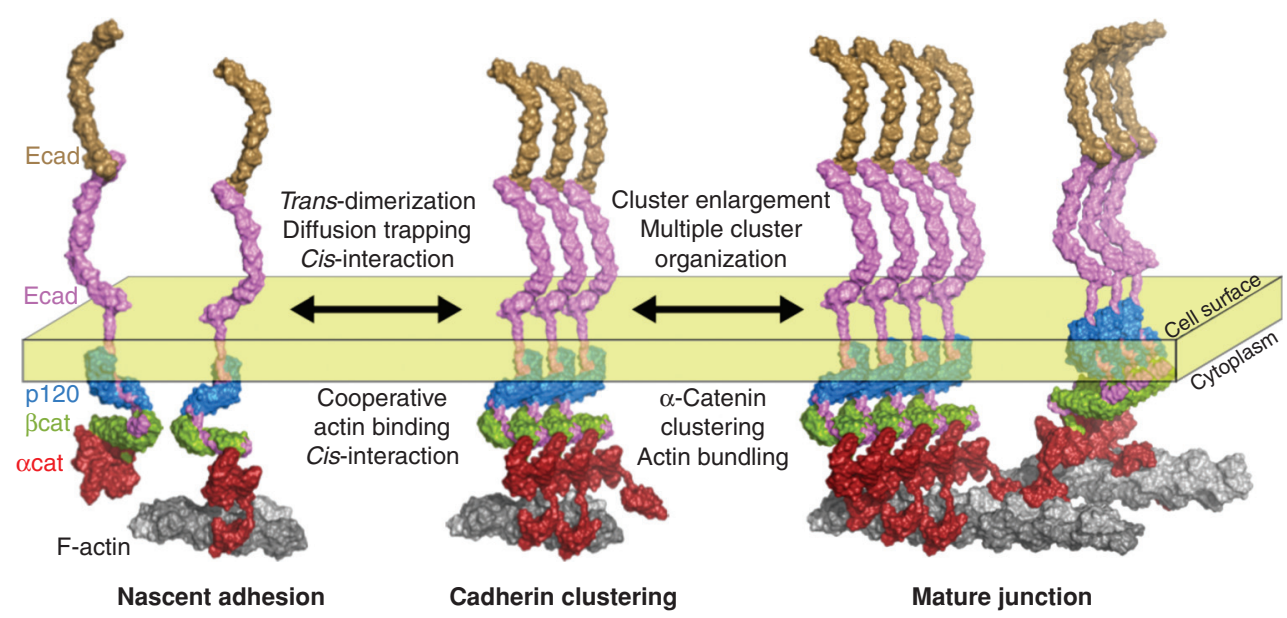

Figure 2. Extra- and intracellular molecular interactions of cadherin clustering. Nascent cell-cell adhesion is mediated by trans-dimerization of cadherin ectodomains from opposing cell surfaces. Small cadherin clusters are formed when cadherin trans-dimers gather at cell adhesion sites through diffusion trapping (Lambert et al. 2007). Cadherin-mediated cell adhesion is strengthened by having $\alpha$-catenin within the cadherin-catenin complex directly binding to F-actin under tension (Buckley et al. 2014). Cadherin clustering is supported by both extra- and intracellular molecular interactions, including trans- and cis-interactions of cadherin ectodomains (Boggon et al. 2002; Harrison et al. 2011) and cooperative F-actin binding of $\alpha$-catenin (Hansen et al. 2013; Buckley et al. 2014). Interactions between the cadherin cytoplasmic tail and p120-catenin are also crucial for cadherin clustering (Yap et al. 1998; Ishiyama et al. 2010). The size of cadherin cluster may increase as cadherin ectodomains organize into a two-dimensional (2D) lattice arrangement (Harrison et al. 2011). Increased local concentration of $\alpha$-catenin through cadherin clustering and multiple $\alpha$-catenins associating with the same actin filament may promote clustering of the $\alpha$-catenin actin-binding domains (Chen et al. 2015) and actin bundling (Rimm et al. 1995), hence further associating multiple cadherin clusters intracellularly through the actin network to form a mature junction. Vinculin has not been considered in this representation, although it plays a major role, because the interface of its interaction with $\alpha$-catenin is only very poorly resolved at the ultrastructural level and because its open/closed conformational switch at adherens junctions is not yet well established. 
While interacting in trans, the cadherin extracellular domain is thought to cluster by cisinteraction to form oligomeric arrays bridging the plasma membranes of the two opposing cells (Harrison et al. 2011; Wu et al. 2011). Extracellular domain interactions trigger interactions of cadherin-associated cytoplasmic proteins with actin filaments (Lambert et al. 2002; Mège et al. 2006). Although it may be convenient to describe the processes governing the integration of cadherin adhesion and cytoskeleton at adherens junctions following this extrato intracellular orientation, the formation, maturation and reshaping of adherens junctions will likely involve back and forth dialogue between these two layers.

\section{CADHERINS ARE CLUSTERED IN MICRON- SCALED STRUCTURES AND OLIGOMERIZED IN NANOASSEMBLIES}

Although the exact ultrastructural distribution of cadherin molecules in adherens junctions remains to be solved, it is clear that cadherins show a range of modes of lateral organization at the plasma membrane, as reviewed recently by Yap et al. (2015). It has been long shown that cadherins accumulate in discrete micron-scaled clusters (microclusters) at nascent adhesion sites (Angres et al. 1996; Yap et al. 1997; Adams et al. 1998; Gavard et al. 2004; Lambert et al. 2007; Cavey and Lecuit 2008; Hong et al. 2013; Wu et al. 2014). More recently, the application of superresolution techniques identified another level of cadherin clustering at the nanoscale level (typically $\sim 50 \mathrm{~nm}$ size, which we will call nanoclusters) (Truong Quang et al. 2013; Wu et al. 2015), indicating that the microclusters observed previously and adherens junctions could result from the aggregation of nanoclusters (Yap et al. 2015).

Microclusters have been proposed to form and grow by a diffusion-trapping process (Delanoe-Ayari et al. 2004; Lambert et al. 2007). At minimum, this process only requires the presence and diffusion of cadherin ectodomains, as long as the plasma membranes of neighboring cells are close enough to allow cadherins to interact by their amino-terminal EC1 domains
( $\sim 38 \mathrm{~nm}$ ) (Boggon et al. 2002; Wu et al. 2011). This passive process requires neither association to catenins and F-actin nor actomyosin generated forces, as it has been shown in cells (Delanoe-Ayari et al. 2004; Harrison et al. 2011) and by using various reconstruction approaches, such as artificial lipid vesicles bearing cadherin molecules that lack their cytoplasmic tails (Harrison et al. 2011) and lipid droplets covered with recombinant cadherin ectodomains (Pontani et al. 2016). Nevertheless, as we will discuss below, this diffusion-trapping clustering process is highly regulated in cells by the association of cadherin/catenin complexes with the actin cytoskeleton and cadherin endocytosis.

The evident advantage of this multiscale molecular clustering is to allow weak, shortlived binding interactions to cooperatively act together as optimized functional architectures (Recouvreux and Lenne 2016; Strale et al. 2015). Indeed, single molecule analysis showed that the lifetime of single cadherin bonds was on the order of seconds to minutes (Perret et al. 2002), although fluorescence recovery after photobleaching (FRAP) experiments on real cell-cell contacts or reconstituted cadherin adhesions indicate the presence of an immobile fraction of cadherins at contact sites with a slow recovery limited by an unbinding reaction rate with characteristic half times $\tau_{1 / 2}=15-$ 20 min (Thoumine et al. 2006; Lambert et al. 2007). Other studies confirmed the presence of an ultraslow exchange fraction of cadherin at adherens junctions in mammalian epithelial cells as well as in Drosophila embryonic epithelium in vivo (Yamada et al. 2005; Cavey et al. 2008). This stabilization could result from an active process requiring actomyosin, as discussed below. However, the mere apposition of the plasma membrane initiated by a few cadherin trans bonds may be sufficient to drive the growth of stable clusters as predicted by modelling approaches (Wu et al. 2013; Mancini et al. 2016). This is reminiscent of modeling performed with other membrane-borne ligand-receptor interactions, such as connexins (Bruinsma et al. 1994). It could be explained phenomenologically as an increase in the probability to form new trans bonds close to preex- 
isting bonds by setting of the distance between the two membranes to one that is optimal for bond formation (Bihr et al. 2012; Wu et al. 2013). In addition, surface proximity may increase the rebinding rate of broken bonds. Finally, modeling of cadherin and connexin cluster formation predicts that discrete clusters will only take place if a negative potential locally counteracts adhesive intercellular bonds (Bihr et al. 2012; Mancini et al. 2016). Indeed, these theoretical analyses predict that, in cases in which a negative (antiadhesive) process would not be present to limit the size of stochastically appearing clusters, these clusters would grow, coalesce or fuse indefinitely until available receptors are depleted. This negative potential could be because of membrane fluctuation or of the presence of molecules in the glycocalyx the size of which is at least one order of magnitude longer than the cadherin ectodomain, as proposed recently for the actomyosin-independent formation of integrin clusters at focal adhesions or much earlier for the formation of gap junctions (Braun et al. 1984; Paszek et al. 2014).

Cadherin clustering is induced by homophilic trans interactions between cadherin EC1 domains as originally described by structural analysis (Boggon et al. 2002). However, more recent X-ray diffraction analysis revealed another interface between EC1 and EC2 domains of cadherins positioned in cis (Harrison et al. 2011). From these data and in silico modeling, it has been predicted that cadherin clusters could be formed by arrays of cadherins organized in oligomers by the repetition along the membrane of trans EC1-EC1 and cis EC1-EC2 interfaces (Fig. 2) (Harrison et al. 2011; Wu et al. 2013). Interestingly, the in silico prediction was that the cis interface could form only after the trans interface, because of its weak binding energy. However, the cooperative interplay between cis and trans interactions would have a major impact on the stabilization of cadherin-cadherin clusters. Although imaged in reconstituted systems (Harrison et al. 2011), it has been difficult to obtain evidence of the formation of these oligomers in cells. The combination of single molecule labeling and immmunogold electron microscopy recently made it possible to visualize oligomeric structure at the plasma membrane of mammal cells (Strale et al. 2015). These nanometric organized oligomers, which displayed a predicted lateral distance of 7-8 nm between single cadherins in the plane of the membrane, were lost in cells expressing cadherins bearing mutations that impaired the formation of the cis interface or when the trans interactions were not formed as predicted by structure and modeling (Harrison et al. 2011; Wu et al. 2013). It was further shown that the cis interface, although not necessary for the formation of macroscopic cadherin clusters and adherens junctions themselves, significantly increases the stability of cell-cell contacts (Strale et al. 2015). This stabilization may result from the cooperative cis and trans interactions between cadherin ectodomains, but also from a cooperative association of oligomer-associated $\alpha$-catenin molecules to actin filaments.

\section{CADHERIN MICRO- AND NANOCLUSTERING AND F-ACTIN ASSOCIATION}

While cadherin microclusters can form in the absence of a functional intracellular domain (Harrison et al. 2011), they are unstable and their lifetime is strongly increased by $\alpha$-catenin mediated coupling to F-actin (Hong et al. 2013). Thus, cadherin cluster formation at actual cell-cell contacts likely results from a combination of passive and active components. The active component requires catenins and $\mathrm{F}$-actin binding, and is involved in cadherin adhesion strengthening (Hong et al. 2013; Lambert et al. 2007; Thoumine et al. 2006). Indeed, the presence of catenin binding sites reduces the diffusive fraction of cadherins at cell-cell contacts as revealed by FRAP experiments. Hong et al. (2013) further showed that F-actin-uncoupled adhesive clusters display high instability and random motion and require the cadherin cisbinding interface. Coupling these clusters with F-actin through an $\alpha$-catenin actin-binding domain dramatically extends cluster lifetime and alleviates the dependence of their formation on the presence of the cis-binding interface. In ad- 
dition, the $\alpha$-catenin actin-binding domain has been shown to cooperatively bind to F-actin (Buckley et al. 2014; Hansen et al. 2013), form clusters on F-actin (Chen et al. 2015) and facilitates actin bundling (Rimm et al. 1995). Thus, the cadherin extracellular region produces intercellular adhesion clusters through trans and cis inter-cadherin bonds, although the intracellular region connects these clusters to the cytoskeleton and may promote further clustering through $\alpha$-catenin (Fig. 2). The cooperative binding to F-actin of multiple $\alpha$-catenins within cis-interface linked cadherin/catenin oligomers may by itself contribute to stabilizing cadherin clusters. Such cooperation, for which the molecular and structural correlates are not yet deciphered, may synchronize extracellular and intracellular binding events in the process of adherens junction assembly.

Cadherin clusters have been shown to grow and move directionally along the orientation of actin cables (Kametani and Takeichi 2007; Lambert et al. 2007). Interestingly, the link of cadherins through $\alpha$-catenin's F-actin binding domain (FABD) conferred directionality to cluster motility (Hong et al. 2013). It is important to note that cadherin oligomers, by construction, are not isotropic (Harrison et al. 2011), in contrast to most of the assemblies formed at the plasma membrane by other transmembrane oligomeric proteins. This raises the question of how the topology of cadherin oligomers may be oriented with respect to their association with oriented F-actin, and its implications for the growth and movement of clusters during adherens junction assembly. In addition, Troyanovsky et al. (2015) recently described a relation between cadherin clusters and clusters of nectin, another cell adhesion molecule present at adherens junctions, the function of which has been underexamined so far. Although cadherins are not required for the basic process of nectin engagement at cell-cell contacts, E-cadherin recruits nectin into adherens junctions, where both proteins form distinct but tightly associated clusters. The recruitment of nectin into composite adherens junctions is mediated by $\alpha$-catenin (Tachibana et al. 2000). Nectins, associated with their cytoplasmic part- ner afadin, cluster on actin filaments aligned because of the clustering of the cadherin/catenin complexes. Whether nectin/afadin clusters could reinforce the actin structure and facilitate further clustering of cadherins is, however, still unclear.

Cadherin clustering has gained much interest over the last three years after the use of highresolution imaging made it possible to prove that cadherins indeed organize into nanoclusters at adherens junctions both in Drosophila and in mammal cells (Truong Quang et al. 2013; Strale et al. 2015; Wu et al. 2015). These studies are complementary but still diverge on many aspects. Using 3D photoactivated localization microscopy (PALM) in living Drosophila embryonic epithelium, Truong Quang et al. (2013) imaged clusters with dispersed sizes ranging from tens to hundreds of cadherin molecules. They showed that these clusters are dynamic, presenting events of fusion and fission. The investigators further suggested that these form by diffusion trapping giving rise to clusters whose size follows a power law. They propose that the maximum size of these clusters is limited by dynamin-dependent E-cadherin endocytosis, which imposes a cutoff size. Moreover, interactions between E-cadherin clusters and actin filaments were shown to control the fission of clusters in a size-dependent manner. Thus, cadherin clustering depends on key cortical regulators, which provide tunable and local control over cadherin organization. Using structured illumination microscopy (SIM) to image fixed mammalian epithelial cells, $\mathrm{Wu}$ et al. (2015) described with higher spatial resolution, slightly smaller clusters having a mean of 6-10 cadherins within domains of around 60 $\mu \mathrm{m}$ size spaced between each other by $100-200$ $\mu \mathrm{m}$. The packing in $60 \mu \mathrm{m}$ domains corresponded to the maximum packing predicted by the cadherin oligomer structure (Harrison et al. 2011). However, Wu et al. (2015) found that these clusters form in the absence of trans and cis interactions, meaning that they may not correspond to the oligomers described in other studies (Strale et al. 2015). One may note, however, that the SIM approach used by Wu et al. (2015), as with the PALM approach developed 
by Truong Quang et al. (2013), does not have the resolution to discriminate between unordered clusters and oligomers.

Wu et al. (2015) reported the presence of cortical F-actin bundles around the cadherin clusters. The investigators proposed that these actin filaments were instrumental in limiting the size of engaged and nonengaged clusters by a corralling effect. Truong Quang et al. (2013) also reported an interaction between Ecadherin clusters and F-actin in Drosophila epithelium and attributed the function of this association to the size-dependent fission of clusters which could contribute to limit the size of clusters, as discussed above. However, these conclusions were mostly drawn from the predictions of a theoretical model, and thus are still waiting for more direct experimental evidence. Interestingly, applying biochemical approaches Troyanovsky et al. (2006) showed that an active cellular process, likely endocytosis, is involved in the disassembly of cadherin adhesive dimers. The inactivation of this process by ATP depletion or by treatments inhibiting endocytosis resulted in the immediate stabilization of cadherin dimers and in a dramatic increase in E-cadherin accumulation at cell-cell contacts. A role for cadherin endocytosis was further suggested by immuno-electron microscopy observations revealing the presence of clathrin-coated pits in the vicinity of adherens junctions. Thus, cadherin endocytosis alone, or in concert with other mechanisms, may indeed control the lifetime of cadherin adhesive dimers, thereby regulating the dynamics and plasticity of cadherin-based adhesive sites.

\section{FORCE-DEPENDENT ANCHORING OF THE CORE ADHESION COMPLEX TO F-ACTIN}

All types of adherens junctions found in epithelial and nonepithelial tissues, despite their difference in stability and/or structure, share a core molecular composition of a cadherin-catenin complex that binds to the contractile actomyosin network. It has become more and more evident that local cortical contractility and in particular Myosin II local recruitment and activation is central in adherens junction forma- tion and stability. For example, positive feedback loops between cadherin engagement, Rho-dependent activation of Myosin II activity and junction reinforcement have been described in mammalian epithelial cells (Ratheesh et al. 2012; Priya et al. 2015). Conversely, during Drosophila germ-band extension, intracellular Myosin II flows are correlated with the resorption of junctions (Rauzi et al. 2010). There is also evidence to suggest that mechanical forces can influence other aspects of the junctional cytoskeleton, such as the dynamics of actin assembly (Leerberg et al. 2014) (for additional details see Yap 2016).

The stability and mechanical strength of adherens junctions also depend on the extent and topology of the association of cadherin/catenin complexes to F-actin, which is also under the control of Myosin II generated forces (le Duc et al. 2010; Yonemura et al. 2010). Recent studies revealed that the cadherin-F-actin linkage during cell-cell contacts remodeling involves the $\alpha$-catenin/myosin II-dependent recruitment of vinculin. (le Duc et al. 2010; Yonemura et al. 2010). However, at present, this direct mechanosensitive pathway is too complex for its molecular details to be studied directly in cellulo. Thus, in vitro systems with purified proteins have been used, including the application of single-molecule force-clamp spectroscopy, which has led to a major breakthrough in the understanding of the force response of cadherin-catenin complexes (Fig. 3). These studies have been important in reconciling previous biochemical studies that did not find binding of the reconstituted cadherin $/ \beta$-catenin $/ \alpha$-catenin complex to F-actin in the absence of force (Yamada et al. 2005) with cellular studies that indicated a direct functional linkage between the cadherin $/ \beta$-catenin $/ \alpha$-catenin complex and actin filaments (Borghi et al. 2012) and those reporting tension-dependent recruitment of vinculin at cell-cell contacts (le Duc et al. 2010; Yonemura et al. 2010).

Two recent single-molecule studies indeed independently identified the force-dependent binding of $\alpha$-catenin to F-actin (Buckley et al. 2014) and the force-dependent unfolding of $\alpha$-catenin controling its binding to vinculin 


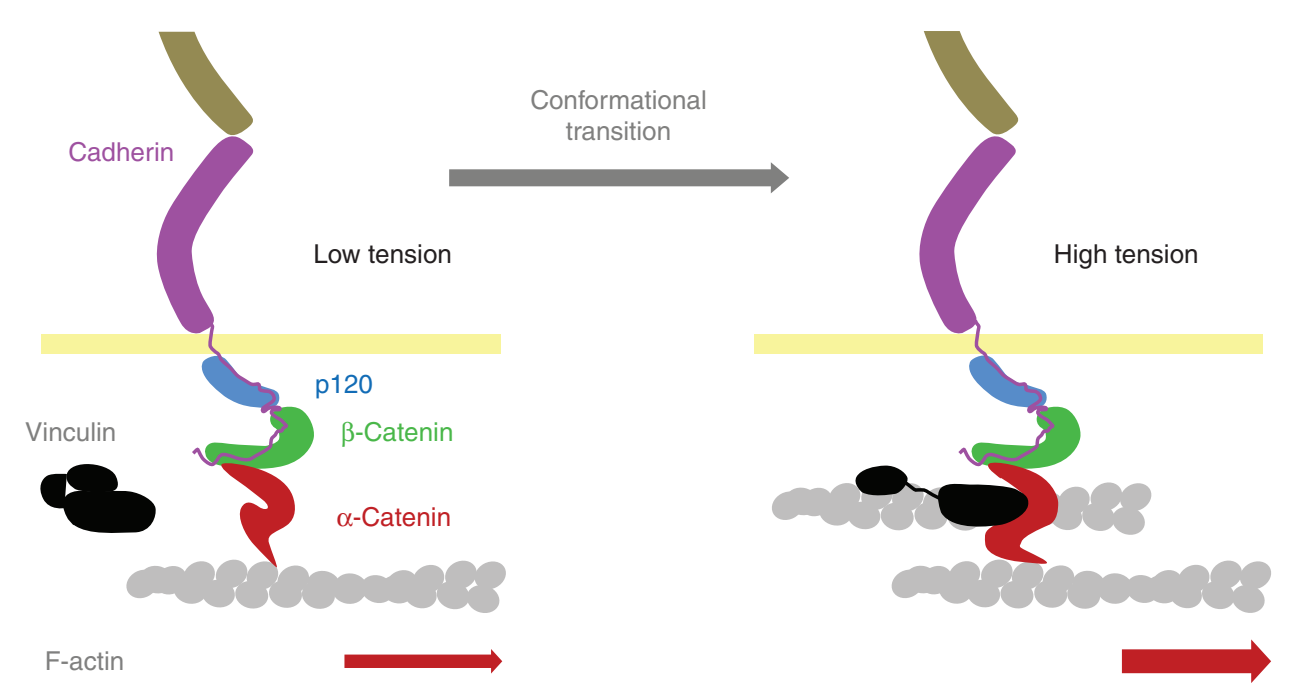

Figure 3. Tension-dependent switch in the cadherin-catenins complex elicits $\alpha$-catenin conformational changes. Two force-dependent reversible transitions in $\alpha$-catenin conformation have been described recently at the single molecule level: one affects the unfolding of the central domain allowing the binding of vinculin (Yao et al. 2014b), the other affects the binding of the carboxyl-terminus domain of the molecule to F-actin (Buckley et al. 2014). The typical force needed for these transitions is around $\sim 5 \mathrm{pN}$. In the cells, this force would be generated by a few Myosin II motors pulling via F-actin on $\alpha$-catenin tethers held under tension by their association with the cadherin-catenins complex in homophilic interaction with cadherins present at the surface of a neighboring cell. The two transitions have been characterized independently with a partial complex, and further studies will be required to determine whether vinculin head binding, blocking $\alpha$-catenin in its open conformation (Yao et al. 2014b), also stabilizes the F-actin binding domain of the molecule in its F-actin high affinity conformation (Buckley et al. 2014). [Adapted from Ladoux et al. (2015) with permission from The Royal Society of Chemistry.]

(Yao et al. 2014b). Together, these suggest that $\alpha$-catenin may undergo force-dependent conformational changes that regulate binding of the minimal cadherin/catenin complex to an actin filament under force. In the study of Buckley et al. (2014), an actin filament was suspended between two optical traps above a reconstituted complex of $\alpha$-catenin $/ \beta$-catenin/cytoplasmic domain of E-cadherin bound to a platform. The platform was moved back and forth to induce force-dependent interactions between the cadherin/ catenin complex and the actin filament. Force stabilized the formation of a cadherin/catenin-F-actin bond that could not form in solution in the absence of force (Yamada et al. 2005). Bond dissociation kinetics could be explained by a 2 -step catch bond in which force shifted the $\alpha$-catenin-F-actin bond from a weak to a strongly bound state. Although the molecular mechanisms underlying this catch bond behavior remain unknown, this likely occurs as the result of a conformational conversion of the FABD domain of $\alpha$-catenin. The force threshold $(4.5 \mathrm{pN})$ of this switch is in the range of forces developed by a few myosin II motors $(2-3 \mathrm{pN})$, and the tension-dependent intramolecular transition may thus contribute to stabilize the association of the cadherin/catenin complex to F-actin under the action generated by myosin II.

A long postulated mechanism for cell-cell adhesion strengthening is the tension-dependent recruitment of the actin-binding protein, vinculin, which was recognized early as a marker of the mature AJ (Watabe-Uchida et al. 1998). More recently, its recruitment at cell-cell contact has been reported to be dependent on myosin II activity (le Duc et al. 2010; Yonemura et al. 2010). Although vinculin may bind $\beta$-catenin (Peng et al. 2010), its binding to a central domain of $\alpha$-catenin (MI) containing the vinculin binding domain (VBD) has been well 
demonstrated (Watabe-Uchida et al. 1998; Choi et al. 2012). Two adjacent domains, MII and MIII, have been reported to inhibit vinculin binding to the VBD domain (Yonemura et al. 2010; Ishiyama et al. 2013). In addition vinculin is recruited to cell-cell contacts on cell stretching, and both vinculin and $\alpha$-catenin are required for strengthening of cell-cell contacts over time (Thomas et al. 2013). Together these data supported the hypothesis that vinculin is recruited in a force-dependent manner to the cadherin/catenin complex on actomyosin force-dependent unfolding of the $\alpha$-catenin central domain (Yonemura et al. 2010). This process would be similar to the binding of vinculin to the talin rod domain on tensiondependent unfolding (del Rio et al. 2009; Yao et al. 2014a), which is thought to be central in cell-extracellular matrix (ECM) adhesion mechanosensing.

Single-molecule force-clamp spectroscopy experiments using magnetic tweezers performed on the central (MI to MIII) domain of $\alpha$-catenin have provided direct evidence of force-dependent unfolding of $\alpha$-catenin and its role in vinculin $/ \alpha$-catenin binding (Yao et al. 2014b). A single $\alpha$-catenin MI-MIII molecule stretched with magnetic tweezers unfolded in three characteristic steps including a reversible step at $4.8 \mathrm{pN}$. This conformational change triggered binding of the vinculin head domain in a 1:1 molar ratio with nanomolar affinity (Yao et al. 2014b). This stretch-induced change in $\alpha$ catenin's conformation involves the destabilization of the intramolecular interactions between the MI domain containing the vinculin binding $\alpha$-helix and the two inhibitory domains, MII and MIII (Ishiyama et al. 2013; Maki et al. 2016), and opening of the MI domain four-helix bundle, resulting in a 1000-fold increase in the affinity for vinculin head (Choi et al. 2012; Rangarajan and Izard 2012). This resulted in very stable binding of $\alpha$-catenin and vinculin head, even after force was released, and prevented $\alpha$ catenin from returning to its closed conformation. Interestingly, the force-dependent binding of vinculin head to $\alpha$-catenin was optimized in a force range of 5-10 $\mathrm{pN}$. The binding was strongly inhibited at forces $<5 \mathrm{pN}$, when MI exists in a stable autoinhibited bundle of $\alpha$-helices. Vinculin was released at forces $>30 \mathrm{pN}$ at which point the vinculin binding $\alpha$-helix of $\alpha$-catenin bound to its head domain was fully unfolded. Thus, as in the case of $\alpha$-catenin/ F-actin binding, vinculin binding to $\alpha$-catenin is dependent on a mechanical signal that causes changes in the conformational equilibrium of $\alpha$-catenin.

These results provided the first direct evidence for the transduction of an acute mechanical signal into a long lasting biochemical signal through two intramolecular tension-dependent reconfigurations of $\alpha$-catenin folding. Further analysis at the single molecule level will allow us to test a more integrated model in which the two transitions could be cooperative and vinculin binding therefore could stabilize F-actin binding and vice versa. Another question is the exact role of vinculin in the cadherin complex: does it just stabilize a conformation of $\alpha$-catenin through its head binding, or does it provide an additional site for the complex to bind Factin? Expression of truncated forms of $\alpha$-catenin alone or fused to E-cadherin deleted from its cytoplasmic domain, already showed that cadherin/catenin complexes can functionally bind to F-actin either by the $\alpha$-catenin FABD alone or by the actin binding side of vinculin alone (Thomas et al. 2013; Chen et al. 2015). However, the complexes directly bound to actin via $\alpha$-catenin actin binding domain were more dynamic than those bound to actin indirectly through vinculin. Further studies will be required to determine whether the association to $\alpha$-catenin increases the binding affinity of the vinculin tail to F-actin (so-called vinculin activation [Cohen et al. 2005; Bois et al. 2006]), and to decipher the kinetics and constants of association and dissociation of $\alpha$-catenin, vinculin, and F-actin, and associated conformational changes in vitro and in cellulo.

\section{THE CORE CADHERIN COMPLEX, ITS REGULATION AND THE CADHERIN ADHESOME}

Although the core cadherin/catenin complex is composed of cadherin, $\alpha$-catenin, $\beta$-catenin, 
p120 and vinculin, one must admit that these five proteins by themselves cannot explain the diversity of the adherens junctions found in different tissues during development and in cancers. This complex is subjected to regulation and in particular to complex phosphorylation of p120, $\beta$-catenin, and cadherin cytoplasmic tail. Accordingly, a large quantity of kinases and phosphatases could be considered as part of a wider cadhesome (Guo et al. 2014). However, as the exact action of these phosphorylations on the anchoring of the complex to Factin is still unclear it will not be discussed here, but the reader is referred to other reviews (Coopman and Djiane 2016; Lilien and Balsamo 2005). A more recent study addressed directly the role of phosphosites found in the flexible linker region of $\alpha$-catenin in between the regulatory region (MI to MIII) and carboxy-terminal part of the protein (FABD) (Escobar et al. 2015). As the central domain of $\alpha$-catenin is responsible for binding important regulatory partners such as vinculin, afadin, and ZO (Zonulae Occludens) proteins, these casein kinase 2 and 1 phosphorylation sites may affect both its binding to F-actin and its modulatory function, in particular its response to force. In Drosophila embryos no obvious defects were found in cadherin/catenin complex assembly or adherens junction formation when these sites were mutated but normal development, collective cell migration, and embryo viability were affected. In mammalian epithelial cells, nonphosphorylatable forms of $\alpha$-catenin induced mild defects in intercellular adhesion but faster and more coordinated cell migrations after scratch wounding suggesting that phosphorylation and dephosphorylation of the $\alpha$ catenin in this region are required for normal cadherin/catenin complex function in Drosophila and mammalian cells (Escobar et al. 2015). Recently, Weis and colleagues identified, in the cadherin tail, a conserved phosphorylation site that controls the interaction between cadherin and $\beta$-catenin in vitro and in vivo (Choi et al. 2015). It was known that phosphorylation of a Ser/Thr-rich region in the cadherin tail dramatically enhances affinity for $\beta$-catenin and promotes cell-cell adhesion in mammalian cell culture systems, but its importance had not been shown in vivo. These investigators showed that the conserved phospho-Ser1212 in Caenorhabiditis elegans cadherin (homologous to Ser686 in murine E-cadherin) is required for binding to $\beta$-catenin and that the loss of Ser1212 phosphorylation produces severe adhesion defects producing developmental abnormalities that resemble full loss-of-function phenotypes.

Recently, wider searches for partners of the cadherin/catenin complex have been performed using proximity biotinylation and quantitative proteomics (Guo et al. 2014; Van Itallie et al. 2014). Van Itallie found known proteins associated with E-cadherin, including catenins and proteins involved in signaling. The most abundant of the proteins identified were catenins, but many others could be rationalized as novel candidates for regulating the adherens junction, cytoskeleton, trafficking or signaling. The investigators further characterized one of them: lipoma preferred partner (LPP), a LIM domain protein which is present at both cellcell contacts and focal adhesions. Knockdown of LPP showed its requirement for E-cadherindependent adhesion and suggested that it plays a role in coordination of cell-cell and cell-substrate cytoskeletal interactions. It has subsequently been shown that LPP inhibits collective cell migration during lung cancer dissemination (Kuriyama et al. 2016). LPP was shown to act through the degradation of $\mathrm{N}$-cadherin via regulating the expression of matrix metalloproteinase 15 (MMP-15). Thus, at this point the role of this protein in the formation and remodeling of cadherin adhesions remains unclear. Guo et al. (2014) using the same approach identified several proteins in the vicinity of the cytoplasmic tail of E-cadherin. By tagging putative E-cadherin-proximal proteins with GFP and determining their subcellular localization, they identified 24 proteins that were previously uncharacterized as part of adherens junctions. In the same study, using a structure-informed database of protein-protein interactions, they constructed an in silico E-cadherin interaction network of 79 published and 394 previously uncharacterized proteins. The same group pro- 
posed a more comprehensive view to classify the members of the cadhesome related to the anchoring of cadherins to F-actin in three categories: transmembrane receptors and membrane binding proteins, adaptor proteins, and F-actin associated proteins (Padmanabhan et al. 2015). However, in the absence of more direct proof for the contribution of these candidates to the regulation of adherens junctions, it is difficult to infer how many will affect the direct link of the complexes to F-actin.

\section{INTERPLAY BETWEEN ADAPTOR PROTEINS}

Although, not systematically picked out by these analyses, three proteins belonging to the adaptor proteins class, in addition to $\alpha$-catenin, play an important role in the association of the complex to F-actin, likely by regulating the association of cadherin/catenin complexes to F-actin: vinculin, afadin, and ZO proteins 1, 2, and 3. While the contribution of vinculin has been the subject of intensive study (as discussed above), the role of $\mathrm{ZO}$ proteins and afadin in the association of cadherin to F-actin and in the regulation of dynamics and mechanical properties of adherens junctions has been illuminated by a recent study from Fanning, Peifer, and colleagues (Choi et al. 2016). Both proteins have been described as direct $\alpha$-catenin binding partners (Itoh et al. 1997; Tachibana et al. 2000; Pokutta et al. 2002). Moreover, the Drosophila afadin homolog Canoe regulates linkage of the actin cytoskeleton to adherens junctions during apical constriction (Sawyer et al. 2009). Choi et al. (2016) used genetic tools and superresolution microscopy in epithelial MDCK cells to analyze how the depletion of $\mathrm{ZO}$ proteins and combined depletion of $\mathrm{ZO} /$ afadin proteins affected the molecular architecture of the epithelial zonula adherens (ZA) and tissue integrity and dynamics.

It had been previously found that depleting ZO family proteins in MDCK cells increases cell junction tension and induces a highly organized contractile actomyosin array at ZA (Fanning et al. 2012; Maiers et al. 2013; Rodgers et al. 2013). ZO proteins knockdown elevated contractility, suggesting that $\mathrm{ZO}$ proteins tend to reduce cell cortical tension at adherens junctions. Interestingly, this depletion induced the formation, on each side of the bicellular junctions, of alternating stripes of F-actin and myosin II that resembled minisarcomeres, and which were very similar to what has been described previously at the apical junctions of epithelial cells in the organ of Corti (Ebrahim et al. 2013). In this epithelium, the periodic assemblies of bipolar Myosin II filaments interlaces with perijunctional actin and $\alpha$-actinin to form a continuous belt of muscle-like sarcomeric units $(\sim 400-600 \mathrm{~nm})$ around each epithelial cell (Fig. 4). Remarkably, the sarcomeres of adjacent cells are precisely paired across the junctional line, forming an integrated, transcellular contractile network. Whether discrete clusters of E-cadherin seen by Choi et al. (2016) ensure the pairing of these sarcomeres across the membrane is likely, but remains to be shown. Both studies converge to show that the contraction/relaxation of paired sarcomeres concomitantly impacts changes in apical cell shape and tissue geometry. In both cases, this peculiar organization is associated with a very stable, rigid cell organization with very low tissue dynamics. MDCK cells respond to elevated contractility by increasing junctional afadin. Further depletion of afadin in these cells did not prevent contractile array assembly but dramatically altered cell shape and tissue mechanics. Further, both these two studies point to tricellular junctions as being major sites of tension within epithelial apical junctions (Fig. 4). Indeed, bicellular borders act as independent contractile units, with actin cables anchored end-on to cadherin complexes at tricellular junctions. Accordingly, vinculin and $\alpha$-catenin under its open conformation are specifically accumulated at tricellular junctions and afadin may act at these sites as a robust protein scaffold that maintains ZA architecture.

\section{THE DYNAMIC ADHERENS JUNCTION: AN EMERGING PROPERTY}

The cadherin/catenin complex-F-actin link must be considered as having a capacity for plasticity, to support stable or dynamic interac- 
A

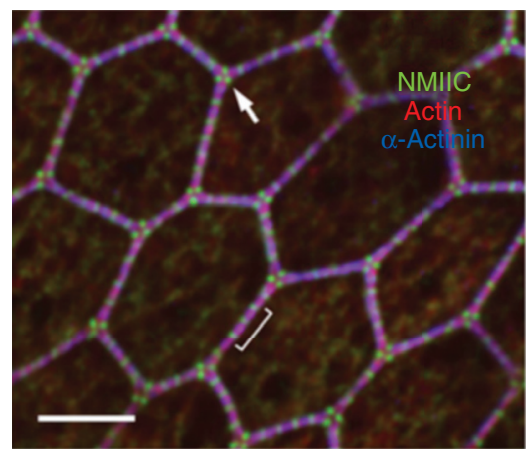

D

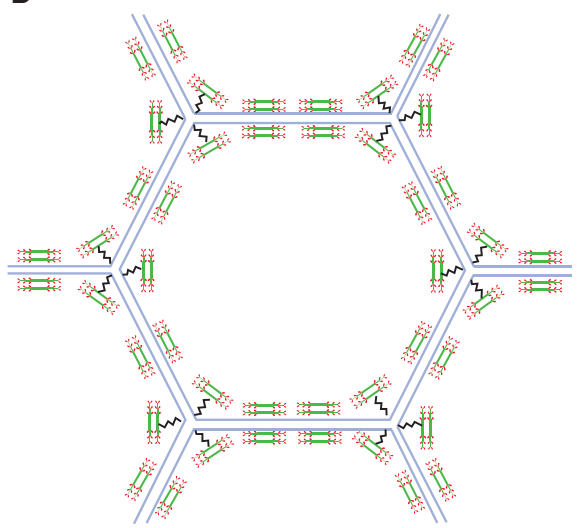

B
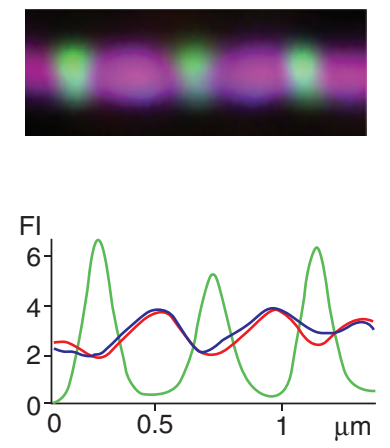

E
C
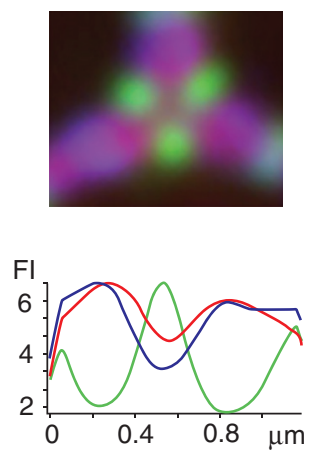

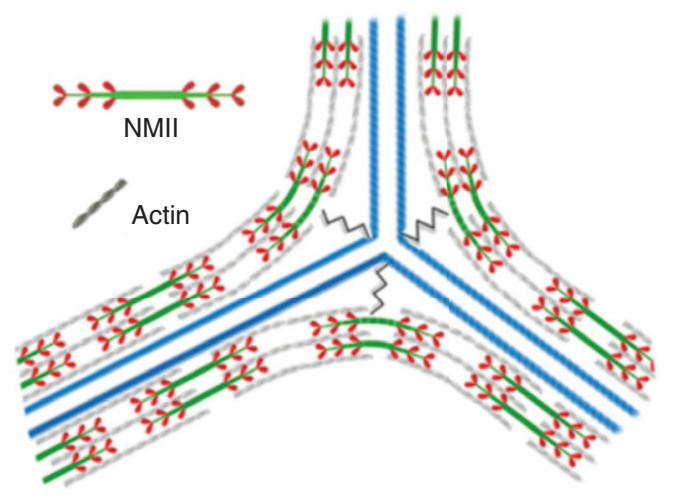

Figure 4. Apical epithelial geometry and alternate distribution of Myosin II and F-actin in sarcomere-like structures along the apical junctional line of organ of Corti. (A) Localization of NMIIC (Myosin IIC, green) and $\alpha$-actinin 1 (blue) in periodic puncta along cell-cell contacts of rat inner sulcus cells (ISCs), with actin in red. Arrow highlights triangular arrangement of NMIIC puncta at tricellular contacts (arrow). (B) Magnification of bracket in (A); below: corresponding fluorescence intensity (FI) profile of NMIIC (green), actin (red), and $\alpha$ actinin1 (blue). (C) Magnification of tricellular junction from $(A)$, showing alternation of NMIIC (green) with actin (red) and $\alpha$-actinin1 (blue); below: corresponding FI profile of NMIIC (green), actin (red), and $\alpha$-actinin1 (blue). Scale bars: $3 \mathrm{~mm}$. (D) Illustration of the relationship of the sarcomeric belt of an epithelial cell and that of six neighboring cells, showing the paring of individual NMII sarcomeres across the junctional line. (E) Model of the arrangement of bipolar NMIIC filaments at a tricellular junction. The "spring-like" symbol represents the putative tether between NMII and the corner of the cell at tricellular contacts. [Panel $A$ reprinted from Ebrahim et al. (2013) with permission from Elsevier (C)2013.]

tions, to account for the diversity of adherens junctions or simple cadherin adhesions as well as for their constant reshaping, in particular when comparing adult epithelia homeostasis and morphogenetic events. In fact cell-cell junctions can be approximated as stable at short time scale (in the range of cell lifetime), although they are clearly dynamic at longer time scale, for example, during tissues reshaping in vivo (Guillot and Lecuit 2013) or collective cell behavior in vitro (Ladoux et al. 2016).

Cell-cell junction dynamics is built in cadherin macromolecular complexes that span over different cellular phases (i.e., the extracellular space, plasma membrane, cytoplasm). This dynamic depends on the proper dynamics of the interactions of cadherin ectodomains and on the dynamics of the cytoskeleton associated to 
the cadherin intracellular domains. Bridging cadherin/catenin complexes dynamics with the one of contractile actomyosin networks will undoubtedly be the next frontier for investigation. Indeed, this raises important conceptual questions which are related to cadherin/ catenin complexes and actomyosin assembling in macromolecular complexes from elementary components belonging to two separate phases: one diffusing in 2D in the plane of the membrane and the other diffusing in $3 \mathrm{D}$ in the cytoplasm. These macromolecular architectures present strong differences in their stability/renewal. For example, F-actin half residence time at cell-cell contacts, as determined by FRAP, is on the order of $0.1 \mathrm{~min}$, and the one of unengaged cadherin at these cell-cell contact sites is around $0.5 \mathrm{~min}$ (Yamada et al. 2005). This is to be compared to the characteristic half time of cadherin engaged in adhesion, which is in the range of 15-20 min (Lambert et al. 2007; Thoumine et al. 2006). Thus, the dynamics of junctions is an emerging multiscale property. In other words, just as we cannot define a human body by the sum of its cells, or a cell as the sum of its organelles, adherens junctions cannot be solely defined by the sum of their protein components. Without taking into account any regulatory pathway, the assembly and turnover of adherens junctions will depend strongly on the initial conditions and on the proper dynamics, association and dissociation kinetics and topology of the interaction between their adhesion and cytoskeletal components. Moreover there are spatial considerations on the associated regulatory pathways to be taken in account to explain, for example, the apical positioning of these junctions in polarized epithelia (Priya et al. 2015).

\section{NEXT FRONTIERS}

Beyond these considerations, further breakthroughs in understanding the molecular and cellular regulations of cadherin/catenin anchoring to $\mathrm{F}$-actin under tension and its relation to cadherin clustering at the cell surface will benefit from the amazing technologies that are now available in the cell biology field. These range from the possibility of measuring forces and stress in situ in living tissues ( $\mathrm{Ng}$ et al. 2014; Sugimura et al. 2016), measuring molecular tensions and conformational changes at cadherin adhesions in vitro (Borghi et al. 2012; Kim et al. 2015) and in vivo (Cai et al. 2014), measuring cadherin dynamics in vivo (Erami et al. 2016), and measuring at nanometer resolution the layering of adhesome proteins within adherens junctions (Bertocchi et al. 2016). This is expected to allow us to gather dynamic and quantitative information on the evolution of the microcomplexes and nanocomplexes forming adherens junctions during physiological processes. It will be of particular interest to obtain stoichiometric and kinetic information that can be integrated with the data obtained with more reductionist, reconstructive approaches using purified constituents.

\section{ACKNOWLEDGMENTS}

R.M.M.'s laboratory was supported by grants from CNRS, Université Paris-Diderot, NUSSPC joined program, Fondation ARC, Human Frontier Science Program (HFSP) grant RPG0040/2012 (B.L., R.M.M.), Agence Nationale de la Recherche (ANR 2010 Blan1515). We thank the member of the Cell Adhesion and Mechanics group, and Benoit Ladoux for discussions and constant support, as well as colleagues of the Institut Jacques Monod.

\section{REFERENCES}

* Reference is also in this collection.

Aberle H, Butz S, Stappert J, Weissig H, Kemler R, Hoschuetzky H. 1994. Assembly of the cadherin-catenin complex in vitro with recombinant proteins. J Cell Sci 107: 3655-3663.

Adams CL, Chen YT, Smith SJ, Nelson WJ. 1998. Mechanisms of epithelial cell-cell adhesion and cell compaction revealed by high-resolution tracking of E-cadherin-green fluorescent protein. J Cell Biol 142: 11051119.

Angres B, Barth A, Nelson WJ. 1996. Mechanism for transition from initial to stable cell-cell adhesion: Kinetic analysis of E-cadherin-mediated adhesion using a quantitative adhesion assay. J Cell Biol 134: 549-557.

Bazellieres E, Conte V, Elosegui-Artola A, Serra-Picamal X, Bintanel-Morcillo M, Roca-Cusachs P, Munoz JJ, Sales- 
Pardo M, Guimera R, Trepat X. 2015. Control of cell-cell forces and collective cell dynamics by the intercellular adhesome. Nat Cell Biol 17: 409-420.

Bertocchi C, Wang Y, Ravasio A, Hara Y, Wu Y, Sailov T, Baird MA, Davidson MW, Zaidel-Bar R, Toyama Y, Ladoux B, Mège RM, Kanchanawong P. 2016. Nanoscale architecture of cadherin-based cell adhesions. Nat Cell Biol. doi $10.1038 / \mathrm{ncb} 3456$.

Bihr T, Seifert U, Smith AS. 2012. Nucleation of ligandreceptor domains in membrane adhesion. Phys Rev Lett 109: 258101 .

Boggon TJ, Murray J, Chappuis-Flament S, Wong E, Gumbiner BM, Shapiro L. 2002. C-cadherin ectodomain structure and implications for cell adhesion mechanisms. Science 296: $1308-1313$

Bois PRJ, O’Hara BP, Nietlispach D, Kirkpatrick J, Izard T. 2006. The vinculin binding sites of talin and $\alpha$-actinin are sufficient to activate vinculin. J Biol Chem 281: 72287236.

Borghi N, Sorokina M, Shcherbakova OG, Weis WI, Pruitt BL, Nelson WJ, Dunn AR. 2012. E-cadherin is under constitutive actomyosin-generated tension that is increased at cell-cell contacts upon externally applied stretch. Proc Natl Acad Sci 109: 12568-12573.

Brackenbury R, Thiery JP, Rutishauser U, Edelman GM. 1977. Adhesion among neural cells of the chick embryo. I. An immunological assay for molecules involved in cell-cell binding. J Biol Chem 252: 6835-6840.

Braun J, Abney JR, Owicki JC. 1984. How a gap junction maintains its structure. Nature 310: 316-318.

Bruinsma R, Goulian M, Pincus P. 1994. Self-assembly of membrane junctions. Biophys J 67: 746-750.

Buckley CD, Tan J, Anderson KL, Hanein D, Volkmann N, Weis WI, Nelson WJ, Dunn AR. 2014. Cell adhesion. The minimal cadherin-catenin complex binds to actin filaments under force. Science 346: 1254211.

Cai D, Chen, Prasad M, He L, Wang X, Choesmel-Cadamuro V, Sawyer JK, Danuser G, Montell DJ. 2014. Mechanical feedback through E-cadherin promotes direction sensing during collective cell migration. Cell 157: $1146-1159$.

Cavey M, Lecuit T. 2008. Imaging cellular and molecular dynamics in live embryos using fluorescent proteins. Methods Mol Biol 420: 219-238.

Cavey M, Rauzi M, Lenne PF, Lecuit T. 2008. A two-tiered mechanism for stabilization and immobilization of Ecadherin. Nature 453: 751-756.

Chen CS, Hong S, Indra I, Sergeeva AP, Troyanovsky RB, Shapiro L, Honig B, Troyanovsky SM. 2015. $\alpha$-Cateninmediated cadherin clustering couples cadherin and actin dynamics. J Cell Biol 210: 647-661.

Choi HJ, Pokutta S, Cadwell GW, Bobkov AA, Bankston LA, Liddington RC, Weis WI. 2012. $\alpha$ E-catenin is an autoinhibited molecule that coactivates vinculin. Proc Natl Acad Sci 109: 8576-8581.

Choi HJ, Loveless T, Lynch AM, Bang I, Hardin J, Weis WI. 2015. A conserved phosphorylation switch controls the interaction between cadherin and $\beta$-catenin in vitro and in vivo. Dev Cell 33: 82-93.

Choi W, Acharya BR, Peyret G, Fardin MA, Mège RM, Ladoux B, Yap AS, Fanning AS, Peifer M. 2016. Remodeling the zonula adherens in response to tension and the role of afadin in this response. J Cell Biol 213: 243-260.

Cohen DM, Chen H, Johnson RP, Choudhury B, Craig SW. 2005. Two distinct head-tail interfaces cooperate to suppress activation of vinculin by talin. J Biol Chem 280: 17109-17117.

Cong Y, Topf M, Sali A, Matsudaira P, Dougherty M, Chiu W, Schmid MF. 2008. Crystallographic conformers of actin in a biologically active bundle of filaments. J Mol Biol 375: 331-336.

Coopman P, Djiane A. 2016. Adherens junction and E-cadherin complex regulation by epithelial polarity. Cell Mol Life Sci 73: 3535-3553.

de Beco S, Perney JB, Coscoy S, Amblard F. 2015. Mechanosensitive adaptation of E-cadherin turnover across adherens junctions. PLoS ONE 10: e0128281.

del Rio A, Perez-Jimenez R, Liu R, Roca-Cusachs P, Fernandez JM, Sheetz MP. 2009. Stretching single talin rod molecules activates vinculin binding. Science 323: 638-641.

DeLano WL. 2008. The PyMOL Molecular Graphics System. DeLano Scientific LLC, Palo Alto, CA, USA.

Delanoe-Ayari H, Al Kurdi R, Vallade M, Gulino-Debrac D, Riveline D. 2004. Membrane and acto-myosin tension promote clustering of adhesion proteins. Proc Natl Acad Sci 101: 2229-2234.

Doxzen K, Vedula SR, Leong MC, Hirata H, Gov NS, Kabla AJ, Ladoux B, Lim CT. 2013. Guidance of collective cell migration by substrate geometry. Integr Biol (Camb) 5: 1026-1035.

Ebrahim S, Fujita T, Millis BA, Kozin E, Ma X, Kawamoto S, Baird MA, Davidson M, Yonemura S, Hisa Y, et al. 2013. NMII forms a contractile transcellular sarcomeric network to regulate apical cell junctions and tissue geometry. Curr Biol 23: 731-736.

Emsley P, Cowtan K. 2004. Coot: Model-building tools for molecular graphics. Acta Crystallogr D Biol Crystallogr 60: 2126-2132.

Erami Z, Herrmann D, Warren SC, Nobis M, McGhee EJ, Lucas MC, Leung W, Reischmann N, Mrowinska A, Schwarz JP, et al. 2016. Intravital FRAP imaging using an E-cadherin-GFP mouse reveals disease- and drug-dependent dynamic regulation of cell-cell junctions in live tissue. Cell Rep 14: 152-167.

Escobar DJ, Desai R, Ishiyama N, Folmsbee SS, Novak MN, Flozak AS, Daugherty RL, Mo R, Nanavati D, Sarpal R, et al. 2015. $\alpha$-Catenin phosphorylation promotes intercellular adhesion through a dual-kinase mechanism. J Cell Sci 128: 1150-1165.

Fanning AS, Van Itallie CM, Anderson JM. 2012. Zonula occludens- 1 and -2 regulate apical cell structure and the zonula adherens cytoskeleton in polarized epithelia. $\mathrm{Mol}$ Biol Cell 23: 577-590.

Farquhar MG, Palade GE. 1963. Junctional complexes in various epithelia. J Cell Biol 17: 375-412.

Gavard J, Lambert M, Grosheva I, Marthiens V, Irinopoulou T, Riou JF, Bershadsky A, Mège RM. 2004. Lamellipodium extension and cadherin adhesion: Two cell responses to cadherin activation relying on distinct signalling pathways. J Cell Sci 117: 257-270. 
Guillot C, Lecuit T. 2013. Mechanics of epithelial tissue homeostasis and morphogenesis. Science 340: 11851189.

Guo Z, Neilson LJ, Zhong H, Murray PS, Zanivan S, ZaidelBar R. 2014. E-cadherin interactome complexity and robustness resolved by quantitative proteomics. Sci Signal 7: rs7.

Hansen SD, Kwiatkowskiz AC, Ouyang CY, Liu H, Pokutta S, Watkins SC, Volkmann N, Hanein D, Weis WI, Mullins $\mathrm{RD}$, et al. 2013. $\alpha \mathrm{E}$-catenin actin-binding domain alters actin filament conformation and regulates binding of nucleation and disassembly factors. Mol Biol Cell 24: $3710-3720$.

Harrison OJ, Jin X, Hong S, Bahna F, Ahlsen G, Brasch J, Wu Y, Vendome J, Felsovalyi K, Hampton CM, et al. 2011. The extracellular architecture of adherens junctions revealed by crystal structures of type I cadherins. Structure 19: $244-256$.

Hatta K, Nose A, Nagafuchi A, Takeichi M. 1988. Cloning and expression of cDNA encoding a neural calcium-dependent cell adhesion molecule: Its identity in the cadherin gene family. J Cell Biol 106: 873-881.

Heisenberg CP, Bellaiche Y. 2013. Forces in tissue morphogenesis and patterning. Cell 153: 948-962.

Holtfreter J. 1939. Gewebeaffinitüt, ein Mittel der embryonalen Formbildung. Arch Exp Zellforsch 23: 169-209.

Holtfreter J. 1964. Gewebeaffinitüt, ein Mittel der embryonalen Formbildung. Revised and reprinted in English. In: Willier BH, Oppenheimer JM, ed. Foundations of Experimental Embryology, pp. 186-225. Prentice-Hall, Englewood Cliffs, NJ

Hong S, Troyanovsky RB, Troyanovsky SM. 2013. Binding to F-actin guides cadherin cluster assembly, stability, and movement. J Cell Biol 201: 131-143.

Huber AH, Weis WI. 2001. The structure of the $\beta$-catenin/ E-cadherin complex and the molecular basis of diverse ligand recognition by $\beta$-catenin. Cell 105: 391-402.

Ishiyama N, Lee SH, Liu S, Li GY, Smith MJ, Reichardt LF, Ikura M. 2010. Dynamic and static interactions between p120 catenin and E-cadherin regulate the stability of cell-cell adhesion. Cell 141: 117-128.

Ishiyama N, Tanaka N, Abe K, Yang YJ, Abbas YM, Umitsu M, Nagar B, Bueler SA, Rubinstein JL, Takeichi M, et al. 2013. An autoinhibited structure of $\alpha$-catenin and its implications for vinculin recruitment to adherens junctions. J Biol Chem 288: 15913-15925.

Itoh M, Nagafuchi A, Moroi S, Tsukita S. 1997. Involvement of ZO-1 in cadherin-based cell adhesion through its direct binding to $\alpha$ catenin and actin filaments. J Cell Biol 138: $181-192$.

Kametani Y, Takeichi M. 2007. Basal-to-apical cadherin flow at cell junctions. Nat Cell Biol 9: 92-98.

Kim TJ, Zheng S, Sun J, Muhamed I, Wu J, Lei L, Kong X, Leckband DE, Wang Y. 2015. Dynamic visualization of $\alpha$ catenin reveals rapid, reversible conformation switching between tension states. Curr Biol 25: 218-224.

Kudo S, Caaveiro JM, Tsumoto K. 2016. Adhesive dimerization of human P-cadherin catalyzed by a chaperone-like mechanism. Structure 24: 1523-1536.

Kuriyama S, Yoshida M, Yano S, Aiba N, Kohno T, Minamiya Y, Goto A, Tanaka M. 2016. LPP inhibits collective cell migration during lung cancer dissemination. Oncogene 35: $952-964$.

Ladoux B, Nelson WJ, Yan J, Mège RM. 2015. The mechanotransduction machinery at work at adherens junctions. Integr Biol (Camb) 7: 1109-1119.

Ladoux B, Mège RM, Trepat X. 2016. Front-rear polarization by mechanical cues: From single cells to tissues. Trends Cell Biol 26: 420-433.

Lambert M, Choquet D, Mège RM. 2002. Dynamics of ligand-induced, Rac1-dependent anchoring of cadherins to the actin cytoskeleton. J Cell Biol 157: 469-479.

Lambert M, Thoumine O, Brevier J, Choquet D, Riveline D, Mège RM. 2007. Nucleation and growth of cadherin adhesions. Exp Cell Res 313: 4025-4040.

le Duc Q, Shi Q, Blonk I, Sonnenberg A, Wang N, Leckband D, de Rooij J. 2010. Vinculin potentiates E-cadherin mechanosensing and is recruited to actin-anchored sites within adherens junctions in a myosin II-dependent manner. J Cell Biol 189: 1107-1115.

Leerberg JM, Gomez GA, Verma S, Moussa EJ, Wu SK, Priya R, Hoffman BD, Grashoff C, Schwartz MA, Yap AS. 2014 Tension-sensitive actin assembly supports contractility at the epithelial zonula adherens. Curr Biol 24: 1689-1699.

Lilien J, Balsamo J. 2005. The regulation of cadherin-mediated adhesion by tyrosine phosphorylation/dephosphorylation of $\beta$-catenin. Curr Opin Cell Biol 17: 459-465.

Liu Z, Tan JL, Cohen DM, Yang MT, Sniadecki NJ, Ruiz SA, Nelson CM, Chen CS. 2010. Mechanical tugging force regulates the size of cell-cell junctions. Proc Natl Acad Sci 107: 9944-9949.

Maiers JL, Peng X, Fanning AS, DeMali KA. 2013. ZO-1 recruitment to $\alpha$-catenin-A novel mechanism for coupling the assembly of tight junctions to adherens junctions. J Cell Sci 126: 3904-3915.

Maki K, Han SW, Hirano Y, Yonemura S, Hakoshima T, Adachi T. 2016. Mechano-adaptive sensory mechanism of $\alpha$-catenin under tension. Sci Rep 6: 24878.

Mancini S, Mège RM, Sarels B, Strale PO. 2016. A phenomenological model of cell-cell adhesion mediated by cadherins. J Math Biol. DOI 10.1007/s00285-016-1072-7.

Matsuzaki F, Mège RM, Jaffe SH, Friedlander DR, Gallin WJ, Goldberg JI, Cunningham BA, Edelman GM. 1990. cDNAs of cell adhesion molecules of different specificity induce changes in cell shape and border formation in cultured S180 cells. J Cell Biol 110: 1239-1252.

Mège RM, Gavard J, Lambert M. 2006. Regulation of cellcell junctions by the cytoskeleton. Curr Opin Cell Biol 18: 541-548.

Mège RM, Matsuzaki F, Gallin WJ, Goldberg JI, Cunningham BA, Edelman GM. 1988. Construction of epithelioid sheets by transfection of mouse sarcoma cells with cDNAs for chicken cell adhesion molecules. Proc Natl Acad Sci 85: 7274-7278.

Nagafuchi A, Takeichi M. 1988. Cell binding function of Ecadherin is regulated by the cytoplasmic domain. $E M B O$ J 7: 3679-3684.

Nelson WJ, Weis WI. 2016. 25 years of tension over actin binding to the cadherin cell adhesion complex: The devil is in the details. Trends Cell Biol 26: 471-473. 
Ng MR, Besser A, Brugge JS, Danuser G. 2014. Mapping the dynamics of force transduction at cell-cell junctions of epithelial clusters. Elife 3: e03282.

Ozawa M, Baribault H, Kemler R. 1989. The cytoplasmic domain of the cell adhesion molecule uvomorulin associates with three independent proteins structurally related in different species. EMBO J 8: 1711-1717.

Padmanabhan A, Rao MV, Wu Y, Zaidel-Bar R. 2015. Jack of all trades: Functional modularity in the adherens junction. Curr Opin Cell Biol 36: 32-40.

Paszek MJ, DuFort CC, Rossier O, Bainer R, Mouw JK, Godula K, Hudak JE, Lakins JN, Wijekoon AC, Cassereau L, et al. 2014. The cancer glycocalyx mechanically primes integrin-mediated growth and survival. Nature 511: 319325.

Peifer M, Yap AS. 2003. Traffic control: p120-catenin acts as a gatekeeper to control the fate of classical cadherins in mammalian cells. J Cell Biol 163: 437-440.

Peng X, Cuff LE, Lawton CD, DeMali KA. 2010. Vinculin regulates cell-surface E-cadherin expression by binding to $\beta$-catenin. J Cell Sci 123: 567-577.

Perret E, Benoliel AM, Nassoy P, Pierres A, Delmas V, Thiery JP, Bongrand P, Feracci H. 2002. Fast dissociation kinetics between individual E-cadherin fragments revealed by flow chamber analysis. EMBO J 21: 2537-2546.

Pokutta S, Weis WI. 2000. Structure of the dimerization and $\beta$-catenin-binding region of $\alpha$-catenin. Mol Cell 5: 533 543.

Pokutta S, Drees F, Takai Y, Nelson WJ, Weis WI. 2002. Biochemical and structural definition of the 1-afadinand actin-binding sites of $\alpha$-catenin. J Biol Chem 277: $18868-18874$

Pontani LL, Jorjadze I, Brujic J. 2016. Cis and trans cooperativity of E-cadherin mediates adhesion in biomimetic lipid droplets. Biophys J 110: 391-399.

Priya R, Gomez GA, Budnar S, Verma S, Cox HL, Hamilton NA, Yap AS. 2015. Feedback regulation through myosin II confers robustness on $\rho \mathrm{A}$ signalling at E-cadherin junctions. Nat Cell Biol 17: 1282-1293.

Rangarajan ES, Izard T. 2012. The cytoskeletal protein $\alpha$-catenin unfurls upon binding to vinculin. J Biol Chem 287: 18492-18499.

Rangarajan ES, Izard T. 2013. Dimer asymmetry defines $\alpha$-catenin interactions. Nat Struct Mol Biol 20: 188-193.

Ratheesh A, Gomez GA, Priya R, Verma S, Kovacs EM, Jiang K, Brown NH, Akhmanova A, Stehbens SJ, Yap AS. 2012. Centralspindlin and $\alpha$-catenin regulate $\rho$ signalling at the epithelial zonula adherens. Nat Cell Biol 14: 818-828.

Rauzi M, Lenne PF, Lecuit T. 2010. Planar polarized actomyosin contractile flows control epithelial junction remodelling. Nature 468: 1110-1114.

Recouvreux P, Lenne PF. 2016. Molecular clustering in the cell: From weak interactions to optimized functional architectures. Curr Opin Cell Biol 38: 18-23.

Reynolds AB, Daniel J, McCrea PD, Wheelock MJ, Wu J, Zhang Z. 1994. Identification of a new catenin: The tyrosine kinase substrate p120cas associates with E-cadherin complexes. Mol Cell Biol 14: 8333-8342.

Rimm DL, Koslov ER, Kebriaei P, Cianci CD, Morrow JS. 1995. $\alpha 1(\mathrm{E})$-catenin is an actin-binding and -bundling protein mediating the attachment of F-actin to the mem- brane adhesion complex. Proc Natl Acad Sci 92: 88138817.

Rodgers LS, Beam MT, Anderson JM, Fanning AS. 2013. Epithelial barrier assembly requires coordinated activity of multiple domains of the tight junction protein $\mathrm{ZO}-1 . J$ Cell Sci 126: 1565-1575.

Samarage CR, White MD, Alvarez YD, Fierro-Gonzalez JC, Henon Y, Jesudason EC, Bissiere S, Fouras A, Plachta N. 2015. Cortical tension allocates the first inner cells of the mammalian embryo. Dev Cell 34: 435-447.

Sawyer JK, Harris NJ, Slep KC, Gaul U, Peifer M. 2009. The Drosophila afadin homologue Canoe regulates linkage of the actin cytoskeleton to adherens junctions during apical constriction. J Cell Biol 186: 57-73.

Strale PO, Duchesne L, Peyret G, Montel L, Nguyen T, Png E, Tampe R, Troyanovsky S, Henon S, Ladoux B, et al. 2015. The formation of ordered nanoclusters controls cadherin anchoring to actin and cell-cell contact fluidity. J Cell Biol 210: 333-346.

Sugimura K, Lenne PF, Graner F. 2016. Measuring forces and stresses in situ in living tissues. Development 143: 186196.

Tachibana K, Nakanishi H, MandaKi Ozaki K, Ikeda W, Yamamoto Y, Nagafuchi A, Tsukita S, Takai Y. 2000. Two cell adhesion molecules, nectin and cadherin, interact through their cytoplasmic domain-associated proteins. J Cell Biol 150: 1161-1176.

Takeichi M. 2014. Dynamic contacts: Rearranging adherens junctions to drive epithelial remodelling. Nat Rev Mol Cell Biol 15: 397-410.

Thiery JP, Brackenbury R, Rutishauser U, Edelman GM. 1977. Adhesion among neural cells of the chick embryo. II. Purification and characterization of a cell adhesion molecule from neural retina. J Biol Chem 252: 68416845.

Thomas WA, Boscher C, Chu YS, Cuvelier D, Martinez-Rico C, Seddiki R, Heysch J, Ladoux B, Thiery JP, Mège RM, et al. 2013. $\alpha$-Catenin and vinculin cooperate to promote high E-cadherin-based adhesion strength. J Biol Chem 288: 4957-4969.

Thoumine O, Lambert M, Mège RM, Choquet D. 2006. Regulation of $\mathrm{N}$-cadherin dynamics at neuronal contacts by ligand binding and cytoskeletal coupling. Mol Biol Cell 17: $862-875$.

Troyanovsky RB, Sokolov EP, Troyanovsky SM. 2006. Endocytosis of cadherin from intracellular junctions is the driving force for cadherin adhesive dimer disassembly. Mol Biol Cell 17: 3484-3493.

Troyanovsky RB, Indra I, Chen CS, Hong S, Troyanovsky SM. 2015. Cadherin controls nectin recruitment into adherens junctions by remodeling the actin cytoskeleton. $J$ Cell Sci 128: 140-149.

Truong Quang BA, Mani M, Markova O, Lecuit T, Lenne PF. 2013. Principles of E-cadherin supramolecular organization in vivo. Curr Biol 23: 2197-2207.

Urushihara H, Takeichi M, Hakura A, Okada TS. 1976. Different cation requirements for aggregation of BHK cells and their transformed derivatives. J Cell Sci 22: 685-695.

Van Itallie CM, Tietgens AJ, Aponte A, Fredriksson K, Fanning AS, Gucek M, Anderson JM. 2014. Biotin ligase tagging identifies proteins proximal to E-cadherin, in- 
R. M. Mège and N. Ishiyama

cluding lipoma preferred partner, a regulator of epithelial cell-cell and cell-substrate adhesion. J Cell Sci 127: 885895.

Vedula SR, Leong MC, Lai TL, Hersen P, Kabla AJ, Lim CT, Ladoux B. 2012. Emerging modes of collective cell migration induced by geometrical constraints. Proc Natl Acad Sci 109: 12974-12979.

Volk T, Geiger B. 1986. A-CAM: A 135-kD receptor of intercellular adherens junctions. I. Immunoelectron microscopic localization and biochemical studies. J Cell Biol 103: $1441-1450$.

Watabe-Uchida M, Uchida N, Imamura Y, Nagafuchi A, Fujimoto K, Uemura T, Vermeulen S, van Roy F, Adamson ED, Takeichi M. 1998. $\alpha$-Catenin-vinculin interaction functions to organize the apical junctional complex in epithelial cells. J Cell Biol 142: 847-857.

Weng M, Wieschaus E. 2016. Myosin-dependent remodeling of adherens junctions protects junctions from Snaildependent disassembly. J Cell Biol 212: 219-229.

Wilson HV. 1907. On some phenomena of coalescence and regeneration in sponges. J Exp Zool 5: 245-258.

Wu Y, Honig B, Ben-Shaul A. 2013. Theory and simulations of adhesion receptor dimerization on membrane surfaces. Biophys J 104: 1221-1229.

Wu SK, Gomez GA, Michael M, Verma S, Cox HL, Lefevre JG, Parton RG, Hamilton NA, Neufeld Z, Yap A.S. 2014. Cortical F-actin stabilization generates apical-lateral patterns of junctional contractility that integrate cells into epithelia. Nat Cell Biol 16: 167-178.

Wu Y, Kanchanawong P, Zaidel-Bar R. 2015. Actin-delimited adhesion-independent clustering of e-cadherin forms the nanoscale building blocks of adherens junctions. Dev Cell 32: 139-154.

Yamada S, Pokutta S, Drees F, Weis WI, Nelson WJ. 2005. Deconstructing the cadherin-catenin-actin complex. Cell 123: 889-901.

Yao M, Goult BT, Chen H, Cong P, Sheetz MP, Yan J. 2014a. Mechanical activation of vinculin binding to talin locks talin in an unfolded conformation. Sci Rep 4: 4610.

Yao M, Qiu W, Liu R, Efremov AK, Cong P, Seddiki R, Payre M, Lim CT, Ladoux B, Mège RM, et al. 2014b. Forcedependent conformational switch of $\alpha$-catenin controls vinculin binding. Nat Commun 5: 4525.

* Yap AS. 2016. Mechanosensing and mechanotransduction at cell-cell junctions. Cold Spring Harb Perspect Biol. doi: 10.1101/cshperspect.a028761.

Yap AS, Brieher WM, Pruschy M, Gumbiner BM. 1997. Lateral clustering of the adhesive ectodomain: A fundamental determinant of cadherin function. Curr Biol 7: 308-315.

Yap AS, Niessen CM, Gumbiner BM. 1998. The juxtamembrane region of the cadherin cytoplasmic tail supports lateral clustering, adhesive strengthening, and interaction with p120ctn. J Cell Biol 141: 779-789.

Yap AS, Gomez GA, Parton RG. 2015. Adherens junctions revisualized: Organizing cadherins as nanoassemblies. Dev Cell 35: 12-20.

Yonemura S, Wada Y, Watanabe T, Nagafuchi A, Shibata M. 2010. $\alpha$-Catenin as a tension transducer that induces adherens junction development. Nat Cell Biol 12: $533-$ 542. 


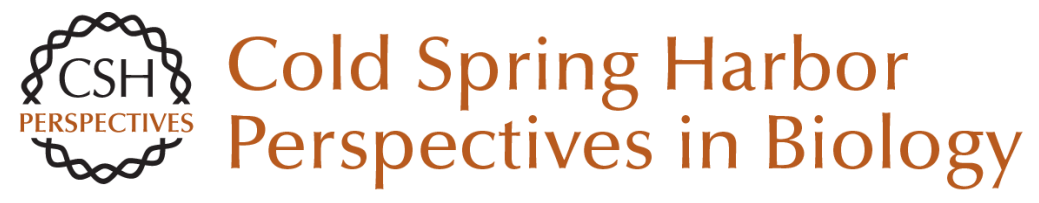

\section{Integration of Cadherin Adhesion and Cytoskeleton at Adherens Junctions}

René Marc Mège and Noboru Ishiyama

Cold Spring Harb Perspect Biol 2017; doi: 10.1101/cshperspect.a028738 originally published online January 17, 2017

\section{Subject Collection Cell-Cell Junctions}

Vascular Endothelial (VE)-Cadherin, Endothelial

Adherens Junctions, and Vascular Disease Maria Grazia Lampugnani, Elisabetta Dejana and Costanza Giampietro

Adherens Junctions and Desmosomes

Coordinate Mechanics and Signaling to

Orchestrate Tissue Morphogenesis and Function:

An Evolutionary Perspective

Matthias Rübsam, Joshua A. Broussard, Sara A. Wickström, et al.

Cell-Cell Contact and Receptor Tyrosine Kinase

Signaling

Christine Chiasson-MacKenzie and Andrea I. McClatchey

Hold Me, but Not Too Tight--Endothelial Cell-Cell Junctions in Angiogenesis

Anna Szymborska and Holger Gerhardt

Connexins and Disease

Mario Delmar, Dale W. Laird, Christian C. Naus, et al.

Cell Junctions in Hippo Signaling Ruchan Karaman and Georg Halder
Signaling by Small GTPases at Cell-Cell Junctions: Protein Interactions Building Control and Networks

Vania Braga

Making Connections: Guidance Cues and

Receptors at Nonneural Cell-Cell Junctions lan V. Beamish, Lindsay Hinck and Timothy E. Kennedy

The Cadherin Superfamily in Neural Circuit Assembly James $D$. Jontes

Mechanosensing and Mechanotransduction at Cell-Cell Junctions Alpha S. Yap, Kinga Duszyc and Virgile Viasnoff

Beyond Cell-Cell Adhesion: Sensational

Cadherins for Hearing and Balance Avinash Jaiganesh, Yoshie Narui, Raul Araya-Secchi, et al.

Cell-Cell Junctions Organize Structural and Signaling Networks Miguel A. Garcia, W. James Nelson and Natalie Chavez

For additional articles in this collection, see http://cshperspectives.cshlp.org/cgi/collection/

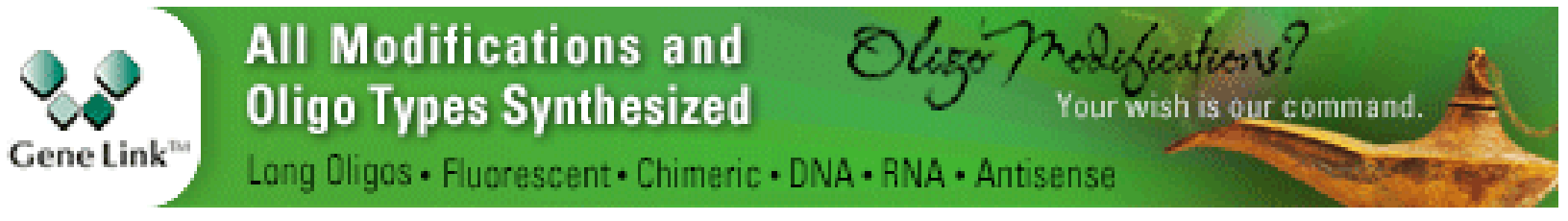


Loss of E-Cadherin-Dependent Cell-Cell Adhesion and the Development and Progression of Cancer Heather C. Bruner and Patrick W.B. Derksen

Desmosomes and Intermediate Filaments: Their Consequences for Tissue Mechanics

Mechthild Hatzfeld, René Keil and Thomas M. Magin
Cell Biology of Tight Junction Barrier Regulation and Mucosal Disease

Aaron Buckley and Jerrold R. Turner

Integration of Cadherin Adhesion and

Cytoskeleton at Adherens Junctions

René Marc Mège and Noboru Ishiyama

For additional articles in this collection, see http://cshperspectives.cshlp.org/cgi/collection/

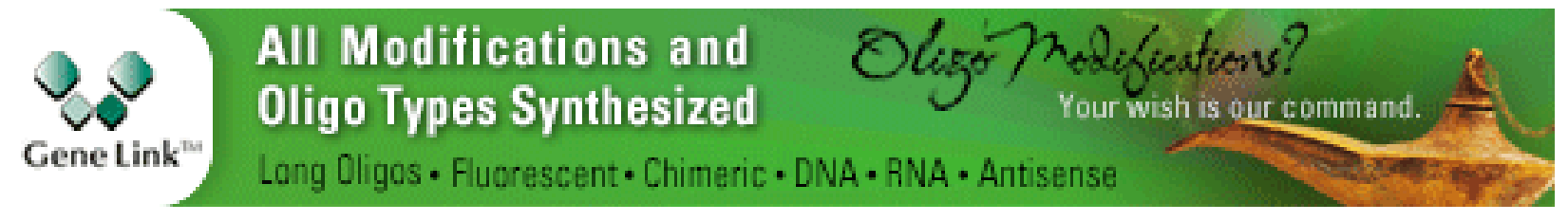

Copyright @ 2017 Cold Spring Harbor Laboratory Press; all rights reserved 